overall patient care by controlling the intake to unified rotational training programmes within national guidelines.

Specialists would then gain advanced clinical experience and attend programmes of continuing education. In due course they would become senior specialists, clinical teachers, medical managers, or whatever they wish. The varied training opportunities available under this scheme would lead to "a wide range of specialist posts."

The future of research and development in medicine is of vital importance to its viability, and there is still a cohort of trainees, albeit a small one, that would not wish to climb this ladder of academic clinical practice.

An academic career could start with a post as lecturer for research minded specialist registrars during the last year of their training. With their certificate of completion of specialist training they would be appointed senior lecturer or assistan professor with clinical specialist status. Each would associate with a reader, associate professor, or a professor and with junior staff form an academic clinical unit. Further progress would depend on the incumbent's performance.

We have an unprecedented opportunity to construct a pattern for postgraduate and continuing professional progress in both clinical and academic practice. Let us not lose it because of rigid outdated and no longer viable concepts.

KE F HOBBS

University Department of Surgery, Professor of surger

Roy

London NW3 $2 \mathrm{OG}$

1 Calman K. Hospital doctors: training for the future. Report of the working group on specialist medical training. London: Health Publications Unit, 1993.

2 Working Party on the Unified Training Grade. Report. Leeds: NHS Executive, 1994

3 Specialist Advisory Committee in General Surgery. Curriculum and organisation for higher surgical training in general surgery and its sub-specialties. A submission to the foint Committee on Highe Surgical Training. London: Royal College of Surgeons, 1994.

4 British Association of Medical Managers Task Group on Medical Manpower. A new breed of consultant? Cheadle, Cheshire: Barnes Hospital, 1994.

5 Roberts J. Rethinking consultants: Specialists in the United States: what lessons? BMF 1995;310:724-7. (18 March.)

\section{Continuing medical education}

\section{Competence and performance are measurable but do not equate with practice}

EDrToR,-T M Hayes's personal view is shared by many doctors, at least in the context of primary care. ${ }^{1}$ In the name of adult education, the continuing medical education industry is growing rapidly-carving out a niche for its existence. The structures are proliferating in the form of mentors, preceptors, cotutors, tutors, clinical supervisors, facilitators, "fellows," and associate and assistan advisers. The processes are also expanding. But, unfortunately, the outcomes are dubious and unproved. Marinker has warned about the rare link between structures, processes, and outcomes. ${ }^{2}$

Although competence and performance are measurable, they do not equate with practice. Performance can focus only on isolated subjects, which are selected for measurement. Practice is more gestalt than performance. One method of personalised continuing medical education is portfolio based learning, ${ }^{3}$ in which the individual learner collects experiential evidence. Crucial to the value of portfolio based learning are identifying further learning needs, documenting how this would be achieved, and monitoring the progress. Though it is relevant, it is labour intensive-and perhaps would be taken on by those who live to learn rather than those who learn to live. Though outcome in the form of health gain for the popula tion cannot be proved, continuing medical education seems to increase the density of the neocortical eators if not the educated.

SIDHA SAMBANDAN General practice continuing education tutor

Division of Continuing Medical Education,

Norfolk and Norwich Institute for Medical Education

Teaching Centre,

Teaching Centre,

Norwich NR1 3SR

1 Hayes TM. Continuing medical education: a personal view. $B M f$ 1995;310:994-6. (15 April.)

2 Marinker M. Experimentation: the next step. Foumal of the Royal College of General Practitioners 1987;37:125-8.

3 Royal College of General Practitioners. Portfolio-based learning in general practice. London: RCGP, 1993. (Occasional paper 63.)

4 Orrell M, Sahakian B. Education and dementia. BMF 1995;310: 951-2. (15 April.)

\section{The suppliers of continuing medical education may be the only ones to benefit}

EDIToR,- T M Hayes argues cogently for linking continuing medical education to audit and peer review. This view, however, may be ignored in the sudden dash towards implementing continuing medical education. The conference of the medical royal colleges and their faculties is already designing formal education programmes and giving approval for various activities of continuing medical education. ${ }^{2}$ Given the background of the purchaser-provider split in the NHS, a boom in the continuing medical education industry, much on the lines of what has happened in the United States, can be expected. The crucial question is "Does continuing medical education improve health outcomes?"

Currently the proposals entail monitoring only the processes constituting such education Courses, conferences, distance learning, and skills upgrading have all been suggested as forming part of the scheme. The initial requirement is for 50 credits (one hour of real educational time) a year with an eventual target of 100 credits a year. ${ }^{2}$

Unless the needs of the scheme are set objectively there is a danger that continuing medical education will become an end in itself. It can be effective only if it is linked to specific outcomes that are defined explicitly at the outset. If we are not careful scarce NHS resources will be wasted on initiatives with unproved effectiveness and the only people to benefit from continuing medical education will be its proliferating suppliers.

Department of Public Health Medicine,

KISHOR PADKI

Coventry Health,

Christchurch House,

Coventry CV1 2CQ

\section{Hayes TM. Continuing medical education: a personal view. $B M$ 1995;310:994-6. (15 April.) \\ 2 Faculty of Public Health Medicine. Continuing professional devel- opment for public health medicine. Implementing the next stages. London: FPHM, 1995.}

\section{College programme will be acceptable to clinicians}

EDITOR,-T M Hayes has an unnecessarily pessimistic view of continuing medical education. ${ }^{1}$ I agree that continuing education has been with us for as long as there has been a medical profession; what is new is that doctors are finding increasing difficulty in keeping up to date with the prodigious growth of knowledge while working within the straitjacket of a health service.

The programme currently being launched by the medical royal colleges is designed to ensure that all career grade physicians have both the time and the opportunities for learning to maintain and improve their competence. The main obstacle to doctors keeping up to date is scarcity of time. The colleges are committed to the provision of protected time for education and to full use of tudy leave. Much medical education is already provided at a local level, and in addition to this many of the specialist societies run successful postgraduate activities around Britain.

In formalising continuing medical education we have aimed at creating a simple, easily documented, and realistic system that will nevertheless be sufficiently robust to withstand scrutiny, As well as providing doctors with a record of their own professional development the programme should yield valuable information on the strengths and weaknesses of medical education throughout Britain.

The style of continuing medical education that we envisage at this college is far removed from that which Hayes fears. We hope that it will be flexible, self developed, and acceptable to doctors.

PETER TOGHILL Director of continuing medical education Royal College of Physicians, London NW1 4LE

1 Hayes TM. Continuing medical education: a personal view. $B M \mp$ 1995;310:994-6. (15 April.)

\section{Assessing quality of economic submissions to the $B M U$}

EDITOR,-Health economics literature has increased exponentially in the past 10 years. ${ }^{1}$ Some authors have expressed concern at the variability of its quality ${ }^{23}$ and the absence of written policies on economic submissions. ${ }^{4}$ We report the results of a pilot study to investigate the $B M \mathcal{F}$ s practices concerning peer review of economic articles and the desirability of criteria for economic submissions.

To assess the difference between accepted and rejected economic manuscripts we examined all submissions to the $B M \mathcal{F}$ from 1 July to 29 September 1994. Of 712 submissions, 28 were economic items $(3.9 \%$ of total submissions $(95 \%$ confidence interval $2 \cdot 6 \%$ to $5 \cdot 6 \%$ )). After authors' names, affiliations, and any other distinguishing items (for example, editing marks) had been removed the submissions were assessed by two reviewers, who scored specific characteristics by answering yes, no, or don't know to questions in checklists assessing methodological and presentational issues.

Papers with an economic component are heterogeneous because of the type of work undertaken and their destination. We identified three types of manuscripts with different editorial fates, which we classified as (a) economic evaluations-studies in which analytical methods are used to define choices in the allocation of resources; $(b)$ economic studies-descriptive and comparative studies, methods, and overviews giving the cost of illness; or (c) other economic papers-letters, opinion pieces, and manuscripts with minimal economic input (for instance, those that mention costs in passing).

A high proportion of economic evaluations were

Fate of economic manuscript by type. Figures are numbers (proportions and 95\% confidence intervals)

\begin{tabular}{|c|c|c|c|}
\hline & $\begin{array}{l}\text { No in } \\
\text { study }\end{array}$ & Refereed & Accepted \\
\hline $\begin{array}{l}\text { Economic } \\
\text { evaluations }\end{array}$ & 5 & $\begin{array}{c}4 \\
(0.80(0.28 \text { to } 0.99))\end{array}$ & $\begin{array}{l}3 \\
(0.60(0.14 \text { to } 0.94))\end{array}$ \\
\hline $\begin{array}{l}\text { Economic } \\
\text { studies }\end{array}$ & 14 & $\begin{array}{c}11 \\
(0.78(0.49 \text { to } 0.95)\end{array}$ & $(0.07(0.01$ to 0.33$))$ \\
\hline $\begin{array}{l}\text { Other } \\
\text { economic } \\
\text { papers }\end{array}$ & 9 & $\begin{array}{c}2 \\
(0.02(0.02 \text { to } 0.60))\end{array}$ & $\begin{array}{c}0 \\
(0(0 \text { to } 0.33))\end{array}$ \\
\hline
\end{tabular}

refereed and accepted, but most economic studies were refereed and rejected (table). We found high overall concordance between the $B M \mathcal{F}$ s and reviewers' decisions for economic evaluations, 